Article

\title{
Vegetarianism/Veganism: A Way to Feel Good
}

\author{
Johannes Simons ${ }^{1, *(\mathbb{C}, \text { Carl Vierboom }}{ }^{2}$, Jeanette Klink-Lehmann ${ }^{1, *} \mathbb{C}$, Ingo Härlen ${ }^{3}$ and Monika Hartmann ${ }^{1}$ \\ 1 Department of Agricultural and Food Market Research, Institute for Food and Resource Economics, \\ University of Bonn, 53115 Bonn, Germany; monika.hartmann@ilr.uni-bonn.de \\ 2 Vierboom \& Partner//Wirtschaftspsychologen, Gartenstr. 30, 53773 Hennef, Germany; info@vierboom.de \\ 3 Traffic Psychological Diagnostics and Consulting, Hummelweg 4, 30900 Wedemark, Germany; \\ haerlen@wirtschaftspsychologen.de \\ * Correspondence: johannes.simons@ilr.uni-bonn.de (J.S.); jeanette.klink@ilr.uni-bonn.de (J.K.-L.)
}

Citation: Simons, J.; Vierboom, C.; Klink-Lehmann, J.; Härlen, I.; Hartmann, M. Vegetarianism/ Veganism: A Way to Feel Good. Sustainability 2021, 13, 3618. https:// doi.org/10.3390/su13073618

Academic Editor: Rajeev Bhat

Received: 11 February 2021

Accepted: 17 March 2021

Published: 24 March 2021

Publisher's Note: MDPI stays neutral with regard to jurisdictional claims in published maps and institutional affiliations.

Copyright: (c) 2021 by the authors. Licensee MDPI, Basel, Switzerland. This article is an open access article distributed under the terms and conditions of the Creative Commons Attribution (CC BY) license (https:/ / creativecommons.org/licenses/by/ $4.0 /)$.

\begin{abstract}
Previous studies have identified health, the environment and animal welfare as key motivations for becoming and remaining vegetarian/vegan. However, the idea of vegetarianism/veganism appears to have interesting facets that go beyond those drivers. This paper describes and examines this attraction. Twenty-six in depth interviews and two group discussions were conducted using the Morphological Psychology approach, which allows the revelation of conscious as well as unconscious drivers based on the detailed narrations of the interviewees. We conclude that the attractiveness of vegetarianism/veganism cannot only be explained by the classical and conscious motivations of a meatless or animal-free diet such as improving health and animal welfare. It also comprises less conscious or unconscious drivers of vegetarianism/veganism such as empowerment and enrichment, regaining autonomy and creating identity and superiority in addition to and partly through liberation from a meat production system which is perceived as destructive and threatening.
\end{abstract}

Keywords: morphological psychology; qualitative market research; vegetarianism; veganism; (un)conscious drivers

\section{Introduction}

"Natural", "normal" and "necessary": these are, according to Joy [1], the three pillars describing the high prevalence and cultural embeddedness of meat eating in Western societies.

Structural changes in meat production and processing as well as a multitude of meatrelated scandals in Germany have damaged the reputation of the sector [2,3] and led to an image that is often subsumed under the key words "factory farming" [4,5]. The reduced acceptance of modern animal husbandry in German society is expected to lead to a decrease in future meat consumption [6].

So far, however, per capita meat consumption in Germany does not show a downward trend. Between 2006 and 2019, the average meat consumption for human use fluctuated at approximately $60 \mathrm{~kg} /$ head and year with values above $61 \mathrm{~kg} / \mathrm{head} /$ year in 2007, 2010, 2011 (peak with $62.8 \mathrm{~kg} /$ head and year), and 2015 [7]. Meat consumption in 2019 amounts to $59.5 \mathrm{~kg} / \mathrm{head}$.

Even though meat statistics do not reflect changes in overall meat consumption, surveys reveal that between 2015 and 2020 the share of self-reported vegetarians in Germany increased from $7.6 \%$ to $9.3 \%$ and the share of self-reported vegans from $1.2 \%$ to $1.6 \%$, with a higher share for millennials [8-10]. During the same period, the number of vegan restaurants in Germany increased from 137 to 242 [11]. These developments indicate that the idea of vegetarianism/veganism has fascinating facets for parts of the population. The aim of the present paper is to describe and examine to what extent this fascination can be explained by the fact that vegetarianism/veganism addresses fundamental psychological motives. In contrast to previous studies focusing on vegetarianism/veganism, this study is based on Morphological Psychology (MP), an approach that allows for deeper insights into conscious 
and unconscious drivers and for structuring the impact of vegetarianism/veganism on the mind and psyche.

The paper is structured as follows: Section 2 provides an overview with respect to the relevant empirical literature. This is followed by a description of the method applied and the sample of the empirical study (Section 3). The results are presented and discussed in Sections 4 and 5, respectively. The main conclusions are summarized in Section 6.

\section{Literature Insights and Background Information}

The following insights into the literature on vegetarianism and veganism are based on a snowball sampling technique that started with the review article of Ruby [12] and was in a later step complemented by the comprehensive review article of Rosenfeld [13].

Based on this approach, we do not claim to comprehensively represent the results published in the literature on vegetarianism and veganism. However, we were able to draw on a broad range of different articles that summarize the important approaches and relevant results in this research field.

\subsection{Vegetarianism and Veganism-Definition and Perception}

A vegan and vegetarian diet is defined as a diet without animal products or a diet without meat. However, several studies show that self-reported vegetarianism does not necessarily mean a meat-free diet [14,15]. Beardsworth and Keil [14] identified six types of dietary practices of people who refer to themselves as vegetarians. One of those types implies consuming only vegetable products, while another even includes meat, although this is seldom the case. In his literature overview of vegetarianism, Ruby [12] cites several reasons for vegetarians to consume meat, with the enjoyment of eating meat and family pressure being especially important. Greenebaum [16] identifies different strains of arguments that help vegans justify the use of products that are not in line with their ethical beliefs. In contrast to definitions that are based on a specific diet, Shapiro [17] and Rosenfeld [13] describe vegetarianism as a way of living with specific and stable views of oneself, other humans, animals and nature at large.

\subsection{Sociodemographics}

Studies taking into account sociodemographics find a higher share of women amongst vegetarians/vegans [18-23]. Ruby and Heine [24] as well as Modlinska et al. [25] identify different perceptions of meat eaters and vegetarians and conclude that being a vegetarian can make one appear more virtuous but less masculine. Moreover, in their review on the literature about gender differences with respect to vegetarianism and veganism, Modlinska et al. [25] point out a higher-level of empathy towards animals among women, which is in line with a socialization that assigns the role of nurturer and caretaker predominantly to women. This might explain why men feel less inclined to become vegetarian/vegan. Regarding age, the results are ambiguous: in his literature review on vegetarianism/veganism, Rimal [26] concludes that age is positively correlated with the preference for meatless meals. On the contrary, in the studies of Janssen et al. [27] and Kerschke-Risch [20], vegans were significantly younger than the population average. In total, one may conclude that although meat in the diet loses relevance with age, meatless diets are more popular in younger age groups. Ruby [12] points out in his review of the relevant literature that there is some evidence for a positive correlation between vegetarianism on the one hand and education, income, and social class on the other hand.

\subsection{Motivations, Values and Attitudes}

Previous research shows that vegetarianism and veganism are primarily motivated by ethical and health reasons. Piazza et al. [28] and Rothgerber [23] argue that not accepting the use of animals for food is an important factor separating vegetarians/vegans from omnivores. Several authors [2,18,19,29-33] indicate the relevance of animal welfare and environmental considerations for not eating meat and using animal products. 
Ruby and Heine [34] identified disgust as the main determinant for abstaining from eating meat, with disgust being primarily driven by the assumption that animals are intelligent and by animal appearance. This leads to the question of what drives people's perception of animal's intelligence and appearance. According to Joy [1], Bratanova et al. [35] and Loughnan et al. [36], there is evidence that classifying animals as "food animals" influences the perception of their intelligence and appearance and thus helps to reduce moral concerns about eating them.

Another strand of literature concludes that "ethically driven" vegetarianism is rather a specific way of living compared to merely a diet and points to the identity-creating power of vegetarianism [37-39]. One basic issue in the ethical discussions refers to the moral status of animals and the justification of causing suffering and pain to animals (e.g., compare [40,41]. McDonald [42] characterizes the process of becoming vegan as a major change in lifestyle that is based on the rejection of speciesism, while according to Wrenn [43] veganism can be interpreted as part of a movement against globalization. The author explores "vegan abolitionism as a bottom-up, consumer-based resistance movement responding to increasing inequality" [43] (p. 11). Accordingly, Micheletti and McFarland [44] emphasize repercussions of vegetarian lifestyle and consumerism on the meat production system. Adams [45] discusses vegetarianism in the framework of the feminist movement.

As indicated above, health is another relevant motivation for vegetarian/vegan diets [12,46-48]. A meatless diet is perceived as healthier, especially by vegetarians/vegans. Consequently, they expect an improvement in their health status by maintaining or changing to a meatless diet [49]. Beardsworth and Keil [46] also cite gustatory motivations for cutting out meat from the diet. Insight in the psychology of choosing healthy food is provided by von Essen and Englander [50] and von Essen and Mårtensson [51]. From a psychological perspective they describe a healthy diet in the context of a healthy lifestyle as an experience of independence and self-regulation based on carefully listening to the signals of the body. Still a vegetarian diet is not necessarily connected with a healthier lifestyle. Larsson et al. [52,53] point out that in their sample vegetarians and omnivores did not differ in the intake of fruits, alcohol, ice cream, sweets and chocolate or fast food.

Beardsworth and Keil [46] describe the dilemmas inherent in the context of food that are relevant for vegetarianism: (1) food required for energy and health versus food that can lead to illness and disease; (2) food that provides, e.g., gustatory pleasure and satiety versus food that can cause gustatory displeasures, dyspepsia, nausea, and vomiting; and (3) food that is required for living versus food that entails the death of the animals consumed. It can be assumed that omnivores stress the positive health impact and pleasure of eating meat, while vegetarians focus on the negative health impact. Duve [54], who writes about her self-experiment in following a vegetarian, vegan and even fruitarian diet for several months at a time, confirms this conclusion. She not only depicts the difficulties in maintaining the respective diets and corresponding lifestyles; she also describes how her personal experience with nutrition and animal rights reduced repression, created awareness, and changed her attitude and behavior towards animals and meat eating after the experimental period.

\subsection{Transition Process}

McDonald [42] addresses the "process of learning to become vegan" and identifies typical steps that are similar despite individual differences. According to her model the learning process starts with a "catalytic experience" about animal cruelty and either leads to the "repression" of the respective knowledge or to a step she calls "becoming oriented". The latter means intending to learn more and/or make a decision. The subsequent phase is characterized by "learning" more about animal cruelty and about the way of living as vegetarian or vegan. The final "decision" to change to vegetarianism or veganism is not a simple change in diet but it is a comprehensive change in one's "world view" that leads the vegan's lifestyle. Hirschler [55] considers the "process of learning to become a vegan" as an appropriate description to understand the transition process and Maurer [56] 
highlights the relevance of social relations to vegetarians in the process of becoming a vegetarian. The role and relevance of information and communication technology (ICT) in the transformation process to veganism is addressed by Lawo et al. [57]. Besides creating irritation about animal husbandry and support to define a vegan identity, ICT helps to develop necessary practices and knowledge to implement and integrate veganism into everyday life.

\subsection{Vegetarianism/Veganism in Social Contexts}

Several studies address the issues that vegetarians face in their social environment. Asher and Cherry [29] review the sociological literature on food and domestic life to identify factors that hamper the conversion and maintenance of vegetarian or vegan diets in the context of the family. They conclude that negative family reactions play a decisive role in hindering dietary changes. Jabs et al. [15] describe social tensions specific to vegetarians/vegans. They conclude that vegetarians/vegans may manage social interactions and avoid social conflicts by eating animal-derived foods. Greenebaum [58] describes different ways of dealing with conflicts that vegetarians/vegans face in their interactions with meat eaters. Additionally, regarding confrontational strategies, she notices "face-saving" techniques that help vegetarians/vegans to escape attack and alienation. With respect to the range of relations between vegetarians/vegans and omnivores, she summarizes: "The dinner table can be a place that creates warmth and positive memories, or it can be a space for division-a battlefield for family drama" [58] (pp. 322-323). Regarding veganism in a social context, Hirschler [55] emphasizes that interactions with family members in particular were described as difficult by the vegans that he interviewed. However, the reactions of family members were not necessarily opposing but varied between strong disapproval and changing themselves to a vegetarian or vegan diet. Thus, he describes that vegetarians/vegans may succeed in influencing family members and friends to accept or even to change their diet. Beardsworth and Keil [14] address the conflict between children and parents: parents may perceive a vegetarian child as rejecting the parents' food choices and, consequently, they may resist supporting the child. The study of Nezlek et al. [59] shows that vegetarians are more likely to have vegetarian friends and lovers than meat eaters and by that gives evidence for the relevance of the dietary style in the social relations of vegetarians. The various challenges of vegetarians/vegans discussed above are also addressed by Jabs et al. [15]. While the papers mentioned above are primarily based on a sample of vegetarians or vegans, Mylan [60] analyzes barriers to reducing meat consumption and identifies social sanctions like disappointment of others or restrictions in attending social events.

The differentiating power of vegetarianism is addressed by Maurer [56] (p. 9). She draws attention to the opportunity to differentiate oneself from other social groups by following a special diet with restricting rules. Moreover, she notes that a consuming lifestyle can be completely detached from the underlying ideas of individuals or a specific group follow that lifestyle in order to demonstrate power and social status [56] (p. 146).

A myriad of studies address different aspects of vegetarianism/veganism. Beardsworth and Keil [14] note that personal motivations for a vegetarian diet may change over the course of a vegetarian's life. Cooney [61] gives a comprehensive overview of the literature about vegetarians compiling results about sociodemographic and attitudinal differences between vegetarians and omnivores, as well as reasons and barriers for changing to or giving up vegetarianism. In line with Beardsworth and Keil [14] and approximately 25 years later, Cooney [61], as well as the present literature review leads to the conclusion that vegetarians/vegans have numerous motivations for their diet that are not clearly differentiated and that these motivations might change over time. The fundamental question regarding the interpretation of the results is whether moral reasoning leads to dietary change or whether dietary change evokes the justification of moral reasoning [23,62]. MacNair [63] points out that social conflicts between vegetarians/vegans and omnivores as well as self-persuasion may enhance the search for good arguments to justify the diet and/or 
lifestyle. Furthermore, he states that thinking positively about vegetarian food can be an act of self-persuasion to deal with the difficulties of changing the diet. If moral reasoning is not the primary driver but the result of action, some of the underlying reasons why people become vegetarians/vegans remain unknown.

\section{Method and Sample}

This paper is based on the theoretical framework of morphological psychology (MP). The school of MP has its main roots in the theory of gestalt, psychoanalytical theory and phenomenology that are developed for a comprehensive theoretical framework.

- MP stresses the dynamics of psychological development in everyday life and the mechanism that drives these developments [64], while gestalt psychology focuses on gestalt patterns, the morphological approach extends the theory of gestalt to a dynamic and developmental perspective called "gestalt in motion". More specifically, it aims to identify the opposing motivations that determine psychological development. By focusing on dynamics and development, it integrates Goethe's ideas of morphology [64].

- MP acts on the assumption that unconscious and preconscious dimensions influence the behavior and experience of consumers and that there is a reason for the relevant psychological aspects to not become conscious. In line with psychoanalytical theory, it identifies the underlying psychodynamic mechanisms and provides a comprehensive system to explain psychological phenomena. Like psychoanalysis, morphological psychology considers a meaningful structure as given, even if the phenomena do not appear to make sense at first glance [31].

MP does not use psychological personality concepts like traits, values, attitudes or habits. Instead, it focuses on "impacts", which are specific for a product, a service or an idea that people use or cope with. In this regard, MP adopts a particular perspective in performing in depth analyses: it addresses how products, services or ideas help to satisfy personal motivations or provide opportunities in the process of organizing everyday life and its problems.

Based on the paradigm of morphological psychology, the effects of products, services or ideas can be structured in impact units ("Wirkungseinheiten"; the term "Wirkungseinheit" is the technical term used in the context of MP. As there is no unambiguously defined translation into English, we put the German term in brackets in order to emphasize the clear reference to MP). The impact units distinguish between six basic motives that are closely related $[65,66]$. The impact unit is represented in a hexagram (Figure 1).

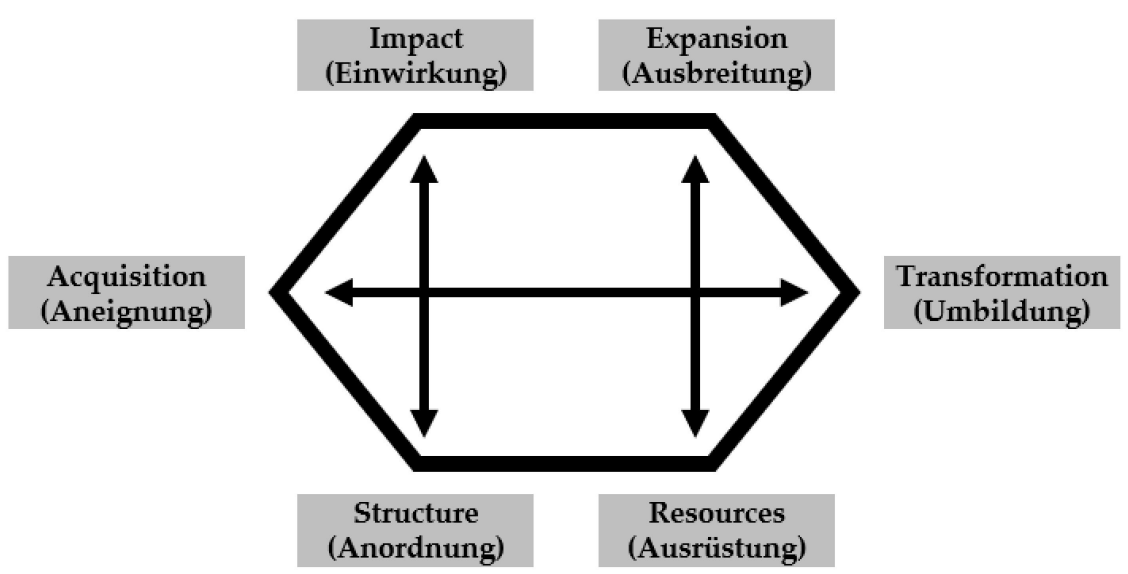

Figure 1. Graphical representation of the impact unit ("Wirkungseinheit") and its fundamental motives. The terms are the technical terms used in the context of MP. As there is no unambiguously defined translation into English, we put the German terms in brackets in order to emphasize the clear reference to MP. 
The six basic motives and their relationship can briefly be described as follows:

- Acquisition and transformation describe the fundamental motive of striving for security, continuity and preserving what has been achieved so far on the one hand, in relation to the striving for change, dynamics and development on the other hand.

- Impact and structure refer to the fundamental motive for individuality, self-positioning and influence in close relation to structure, rules and being embedded in the social environment.

- Expansion and resources capture the fundamental motive for achieving ideals in close relation to a person's abilities and knowledge as well as awareness and acceptance of personal limitations.

Based on MP, the empirical research tries to reveal the conscious as well as unconscious drivers of vegetarianism/veganism. MP gains its insights based on descriptions of phenomena in everyday life obtained in in depth interviews or group discussions and thus follows the ideas of phenomenology. The interviews are a specific type of narrative interview, during which the interviewees describe their everyday life with respect to the phenomena of relevance in the context of the research question. Interviewees are prompted to describe what they observe and experience regarding the issue relevant to answer the research question. Thereby, the interviewee reveals the unconscious context based on detailed descriptions. In line with the narrative paradigm, MP acts on the assumption that the experienced reality of human beings is organized and interpreted in stories. Hence, the stories that interviewees tell in the context of the research issue play an important role in detecting the underlying structure. The interviewer interprets the descriptions and the behavior of the respondents during the interviews, attempts to detect the motivations that can specifically be addressed by the product, service or idea and tests her/his interpretation with additional questions. This also applies to focus groups $[50,67]$.

The success of this process depends on the researchers' ability to empathically understand the expressions of the interviewee [68]. It explicitly uses empathy as a precondition to adequately address the issues relevant to answering the research question. Empathy-the ability to share others' feelings-is essential in human relations and communication, especially in understanding emotions. It requires the specific skills of researchers to cultivate empathy systematically for applying it in diagnosis, therapy, or market research. Beyond the literal words expressed by the study participants, specifically educated researchers uncover the hidden meanings and emotional context [69]. Guided by theory they reconstruct the developing dynamics of the phenomena observed [31].

This procedure is necessarily subjective and interpretative. MP acts on the paradigm that it is imperative to use one's own feelings and experiences as a type of soundboard to understand the narration of the interviewees. To reduce the individual biases caused by the personal entanglement of the interviewer, studies are carried out in a team-based research approach, in which researchers systematically explain, discuss, and adjust their results. Moreover, conducting qualitative research in a team helps to overcome the limits of an individual researcher regarding the perception and interpretation of the described phenomena and the stories that emerge in the interviews.

The research process begins with a self-reflection of the involved researchers about the topic, which forms the starting point. The subsequent interviews and group discussions are considered as collaborative work between researchers and interviewees. They enable researchers to better understand and structure the research. In this respect data collection and analysis are interwoven processes and not successive steps [31]. Moreover, the involved researchers discuss their findings during the interview phase, which helps them to adjust the research process if deemed necessary.

According to the theoretical approach, interviews and group discussions have to be documented with a description of the phenomena rather than with a mere transcript. Those descriptions should include little interpretation [70] because they are used later in the analysis process by other researchers. In addition, interviews and group discussions should be audio- or video recorded to ease further analysis and interpretation in a team. 
Together, the two procedures create transparency regarding the perceived dynamics in interviews and the involvement of the interviewer.

Interviews as well as group discussions normally last for one and a half to two hours. This is not enough time to generate an in depth analysis of the personal motivational structure of an interviewee regarding the issue at stake. However, it is sufficient to detect motivations and their structure, which can be addressed by products, services or ideas, i.e., identifying which personal motivations can be addressed by vegetarianism/veganism.

The MP approach requests for the sample to be psychologically representative. This means that the interviewees cover all relevant aspects of the issues investigated by the research project. Accordingly, the variety of the sample is what matters and not the statistical representativeness concerning, e.g., sociodemographic characteristics. The sample is the core unit that allows for the exploration of the research question and the detection of psychological structures.

The research was conducted in the frame of a project dealing with the societal acceptance of animal husbandry in Germany. Twenty-six in depth interviews and two group discussions (one with eight and one with nine participants) were conducted with selfreported vegetarians $(26 ; 60 \%)$ and vegans $(17 ; 40 \%) .29$ of the participants $(67 \%)$ were female and $14(33 \%)$ were male, with an average age of $35.2(\mathrm{SD}=13.9)($ see Table 1$)$.

Table 1. Composition of the sample of in depth interviews and group discussions.

\begin{tabular}{|c|c|c|}
\hline & In Depth Interviews ( $\mathrm{N}=\mathbf{2 6})$ & Group Discussions $(\mathrm{N}=2)$ \\
\hline \multicolumn{3}{|c|}{ Gender } \\
\hline Male & 9 & 7 \\
\hline Female & 17 & 10 \\
\hline \multicolumn{3}{|c|}{ Kind of meatless diet } \\
\hline Vegetarians & 18 & 8 \\
\hline For less than 2 years & 5 & 0 \\
\hline For 2 years and more & 9 & 1 \\
\hline No information & 4 & 7 \\
\hline Vegans & 8 & 9 \\
\hline For less than 2 years & 1 & 2 \\
\hline For 2 years and more & 6 & 4 \\
\hline No information & 1 & 3 \\
\hline \multicolumn{3}{|c|}{ Age } \\
\hline$\leq 30$ & 18 & 6 \\
\hline $31-50$ & 6 & 8 \\
\hline$>50$ & 2 & 3 \\
\hline \multicolumn{3}{|c|}{ Household size } \\
\hline Single household & 8 & 2 \\
\hline 2 person household & 7 & 1 \\
\hline$>2$ person household & 8 & 1 \\
\hline No information & 3 & 13 \\
\hline
\end{tabular}

The interviews were carried out in different regions to capture aspects that might be influenced by different regional circumstances. We choose Berlin as the center of the German vegetarian/vegan movement (one group discussion, four one-to-one in depth interviews); Cologne/Bonn (one group discussion; two one-to-one in depth interviews) and Bochum (four one-to-one in depth interviews) as large cities in the west of Germany; 
Oldenburg, a city in the center of the German pig, poultry and egg production area (four one-to-one in depth interviews); Kempten, a city in the alpine upland located in a holiday destination with intensive milk production (four one-to-one in depth interviews); Göttingen, located in the center, and Erfurt, located in the east of Germany, are two regions with low relevance to animal husbandry (four one-to-one in depth interviews each). While Berlin, Cologne, Bonn and Bochum are (very) large cities, Oldenburg, Kempten, Erfurt and Göttingen are medium-sized cities surrounded by rural areas.

The participants were primarily recruited by commercial market research institutes. Most of the field research was carried out at the end of 2015. However, to obtain insights into the perspectives of young adult vegetarians/vegans, a few additional interviews were conducted in 2017. The participants were told that the interviews/discussions concerned agriculture and nutrition. Animal welfare or animal husbandry was not explicitly mentioned.

Three interviewers were engaged in the research, one woman (31 years) and two men (58 and 54 years). All three are psychologists with longstanding experience in psychological research. An agricultural economist with a special education in psychological market research completed the core team of the field work. None of the researchers is vegetarian/vegan; still, there were considerable differences regarding closeness to vegetarianism/veganism and the relevance of meat and meat products in the personal diet.

\section{Results}

In line with the MP approach, we differentiate between the narrations of the interviewees and the conclusion, which does not focus on personal histories and motivations but on the opportunities that vegetarianism/veganism offers the psyche. In general, vegetarianism and veganism are perceived as closely related. Vegetarianism appeared as a soft form of veganism. During the interviews and group discussions vegetarians often stated that veganism is a valuable ideal, but that they feel prevented from striving for veganism by the effort that veganism requires in everyday life. Accordingly, in the following paragraphs we do not strictly distinguish between vegetarianism and veganism but describe differences regarding the intensity at which the fundamental motives are addressed. Below, we highlight the difference by presenting the narrations in italics. The results are structured according to the different aspects of vegetarianism/veganism that turned out to be of particular relevance for the study participants. Regarding the opportunities linked to vegetarianism/veganism, potential conflicts and developments are highlighted.

\subsection{Liberation}

Defense against the destructive and threatening power of the meat production system and, as a consequence, the liberation from the system is one basic element driving the attraction of vegetarianism/veganism. The image of animal husbandry revealed by the participants can be summarized with the slogan "factory husbandry" or "factory farming". It is understood to be a sector treating animals as soulless objects and not as fellow creatures. Animals are regarded as creatures that are exploited by humans to maximize profits. Living conditions for animals in the context of "factory farming" are described as narrow, dark, and having a poor air supply.

"Factory husbandry" is perceived as an unacceptable form of treating animals. The evaluation is mainly driven by empathy towards animals. However, "factory farming" is not a mental concept that is restricted to animal husbandry at the farm level but refers to the whole meat value chain. Farmers are regarded as part of a comprehensive system and not as independent actors.

Masses of animals, stables with a length of hundreds of meters, masses of meat, and everything hidden behind closed doors are typical associations mentioned when describing the sector. Animal husbandry was often described as $\mathrm{KZ}$, which is the German abbreviation for concentration camp.

The parallel to a KZ demonstrates that animals are perceived as victims and conveys a high level of moral indignation. Meat, especially if produced in a "factory farm", is not 
perceived as a source of energy, vitality and strength but is rather associated with death and is believed to cause illness and disease. In line with the disgraceful treatment of animals, meat is regarded as devaluated food, which might cause severe negative health impacts.

Frightening pictures and ideas referred to cancer or HIV. Moreover, diseases caused by an overconsumption of meat were mentioned. The production and processing conditions are supposed to spoil meat.

However, it is not necessarily a fundamental rejection of eating meat that leads to abandoning meat and meat products. It is rather the perceived lack of fairness towards the animals in a "factory farming" system that leads to vegetarianism/veganism.

Several participants explained that disgust caused by the production and processing conditions motivated them to give up eating meat. They would not reject eating meat or animal products if produced in a system that preserved the dignity of animals. This is supposed to be a fair deal for the animal. As an example, interviewees refer to small family farms with a limited number of animals that operate as in the "good old days". This farm system is supposed to not produce masses of meat and offers a good life for the animals.

The ideas and images associated with "factory farming" in general are not driven by personal experience but by the media and by peoples' fantasies. The fact that people know little or nothing about animal husbandry from their own experience makes it easy to conjure nightmarish fantasies. Nightmarish pictures and imaginations could be easily activated during the interviews and can cause a high level of discomfort. The use of the KZ image to describe the factory farming system, as well as the link to cancer and HIV, reveals a blurring of the boundaries between the treatment of human and nonhuman beings. Moreover, it demonstrates the experienced threatening power of the system, which still remains even if eating meat is avoided. However, a meatless diet or a lifestyle free from animal products can be experienced as an appropriate measure to prevent the system from occupying one's own body and to become part of the shocking and devaluating machinery of factory farming. At first sight, vegetarianism/veganism offers a simple way out of a situation that causes discomfort and unappetizing pictures. It appears that it is revulsion and abhorrence in line with ethical deliberation and empathy for animals that foster the development of avoiding meat.

The interviewees stated that the process of becoming increasingly aware of the functioning of the meat production system is parallel with growing disgust and nausea. One interviewee summarized that there is no way back for her now that she knows how the system works.

In that context, rejecting meat or animal products is a way to protect oneself from the frightening and nightmarish pictures that spoil one's appetite and lead to a guilty conscience while eating.

For several interviewees, animal welfare and the problems of the meat sector do not play a relevant role in their everyday life. A nonmedical practitioner stated at the end of the interview that he had never thought as much as he did in the last two hours. Another participant said that he does not want to have a close look at animal husbandry conditions because it is masochistic and depresses him.

Abstaining from eating meat or animal products in food can contribute to circumventing triggers that spoil the appetite and to avoiding revulsion. Moreover, changing to a meatless diet can help to restore the pleasure of eating.

Conscious and healthy eating was addressed in the interviews as a starting point for restoring appetite. One woman told us that it is not possible for her to eat meat with a clear conscience. Once she stopped eating meat she was much more aware of the food she ate and regained the pleasure of eating.

However, it is not simply restoring appetite that is relevant. Against the background of a threatening meat production system, vegetarianism/veganism can support a feeling of autonomy if related to disentangling oneself from a food production system that is perceived as immoral and exploitative. Changing to a diet with no meat or even with 
no animal products at all can be experienced as an act of liberation and a relief from the burdens caused by an affluent lifestyle.

The process of becoming vegetarian/vegan was described in combination with the process of gaining awareness of the factory farm system. Abandoning meat was characterized as a process that released the participants from the oppressing power of the meat industry.

"Liberation" can be related to the motives of the unit of effect as follows: The motive of "acquisition" is tackled by a need for protection against a system that is viewed as threatening. However, the enjoyment of eating should also be preserved. In order to achieve this, a development phase is necessary ("transformation") in which the ideals of a vegetarian or vegan lifestyle must be brought into harmony with one's own abilities, habits and everyday limitations (tension between "expansion" and "resources"). Particularly during the transformation phase, changing personal values and habits have to be realigned with existing social-environmental structures and rules. This is captured by the tension between "impact" and "structure".

\subsection{Empowerment and Enrichment}

In line with the act of liberation, the change in diet leads to a feeling of empowerment. Meatless diets are regarded as being in harmony with nature and life in general. Thus, abstaining from eating meat is believed to improve the diet.

Meat produced in "factory farms" was perceived as rotten and devaluated. A diet without this rotten meat was considered to improve health and well-being. However, consuming meat produced in an accepted way was evaluated heterogeneously. Some participants stated that meat from animal-friendly husbandry systems or game is not linked to these negative health effects.

Nevertheless, a vegetarian and especially a vegan diet requires specific strategies to ensure an adequate intake of necessary nutrients that could otherwise compromise health and empowerment.

One nutritionist aware of the shortcomings of a vegan diet has her blood tested regularly. She presents a list to the doctor and tells her what type of tests to arrange. One vegetarian stated that children could die from consuming a vegan diet.

Thus, securing health and well-being while pursuing a vegan diet is perceived as one of the challenges of veganism and a barrier to becoming vegan, despite the awareness that animals are exploited in the dairy or egg sector. From an ethical point of view, a vegan diet appears to be superior. The additional effort a vegan diet requires regarding information, food purchase and preparation, and concerns about a balanced diet were perceived as barriers.

Several participants stated that they did not change to a vegan diet because of expected malnutrition. A childcare worker assumed it was possible to overcome the shortages of a vegan diet through supplements; still, he believed that the supplements were a poorer alternative. A nonmedical practitioner even stated that parents feeding their children a vegan diet should be punished.

Regarding veganism, the tension between ethics, high personal effort and empowerment becomes obvious. Concerns related to a balanced diet reveal the perceived limits of a vegan diet and/or an unwillingness to make the necessary effort. Additionally, empowerment can be experienced by deviating from usual diets, by learning more about nutrition, trying new food and by mastering the challenge of becoming vegetarian/vegan.

Vegetarians/vegans referred to difficulties in coping with abstaining from the pleasure of eating meat. They compared giving up meat consumption with withdrawal symptoms from drug or nicotine abstinence. They mentioned transition periods in which they gradually reduced the consumption of meat or all animal products. In addition, they reported a number of issues concerning detrimental factory husbandry.

Rearranging one's life is one challenge in vegetarianism and especially veganism, which goes beyond abstaining from meat/animal products while ensuring a balanced diet 
but also refers to distinguishing vegan products from those that are not. While unprocessed products can easily be classified, this does not hold for processed products. Moreover, it is not easy in all cases to draw the line between vegan and nonvegan products.

One participant reported that the adhesive used to fix the labels to beer bottles often contains animal products. Consequently, he would drink beer only from brands that use vegan adhesives.

This reveals that the apparently simple rules - either "no meat" or "no animal products"are in many ways difficult to implement in everyday life and can put significant pressure on those who are devoted to vegetarianism/veganism.

Several participants admitted to breaking the rules. Vegans wore leather shoes or sometimes ate cake that contained eggs. Some vegetarians ate fish, and others expressed their regret that they were not strong enough to become vegan. The participants dealt differently with exemptions from the rules, but some felt guilty and weak.

Given this background, vegetarianism and, even more so, veganism can be a personal challenge, and succeeding in this challenge denotes personal triumph. Enrichments in the diet that originate in the restrictive food choice and, as a consequence, new taste experiences can be classified as the bright side of vegetarianism/veganism.

Several participants describe new and more exciting taste experiences, a more diversified diet as well as new and better body awareness as a reward for mastering the task. The restriction of not eating meat or animal products was described as a starting point for enriching the diet with products that were formerly unknown.

Obviously there is a tension as well as a complement between restriction and enrichment with enrichment following restriction. Accordingly the reward offered by a change to vegetarianism/veganism is not only mastering a challenge but also discovering new worlds of taste.

Enrichment and restriction were two of the contentious issues in the researchers' team meetings. The restrictive aspect of vegetarianism/veganism was especially emphasized by research with a higher relevance of meat in the diet. Accordingly, they considered statements about enrichment mainly as an act of self-persuasion. In contrast, those more devoted to vegetarianism/veganism stressed the aspect of enrichment as a true feeling of experiencing new dimensions. Finally, we concluded that there is a tension as well as a complement between restriction and enrichment that can be characterized with the Latin phrase: per aspera ad astra ("through hardships to the stars") and the feeling of restrictions can also lead to self-persuasion in order to overcome temptations of eating meat.

The simpler vegetarianism/veganism becomes, the less the challenge and the reward for succeeding in the challenge.

Several interviewees criticized, for example, meatless meat alternatives as not being truly vegan or vegetarian.

Meatless meat products alleviate the change in the diet. Therefore, they reduce the effort involved, making it easier to overcome the barrier of not eating meat, and decrease the personal valuation of what has been achieved. Vegetarianism and especially veganism can be part of broader societal criticism. Not only is factory husbandry questioned, but an affluent society that exploits nature as well as animals leads to what is perceived as a standardized and unnatural sense of taste and creates nonsustainable consumption patterns.

Several interviewees indicated their preference for organic food or small-scale food distribution systems and criticized the engagement of the meat industry in producing meatless meat products.

With major (meat) companies increasingly being the entities that produce vegetarian or vegan food, consuming these products contradicts the motivation of establishing an alternative lifestyle because it integrates vegetarianism and veganism into the conventional meat system, which activates the nightmarish images of "factory farming"'. Vegetarianism/veganism provides an opportunity to be part of a social movement that opposes societal and economic development that is considered undesired. In contrast to political movements, it is not necessary to join a specific group or political party. It is possible to 
actively oppose the current "evil" system by restricting one's diet. Protest can refer to the meat production system, but it can also address food production or nutrition at a more general level.

One interviewee was employed by a vegetarian organization and additionally was a supporting member of an animal rights organization. Another interviewee receives information from such groups via Facebook. However, many interviewees did not actively participate in an animal welfare/right organization. Interviewees rather mentioned individual activities and not about joint actions against the system.

Against this background, vegetarianism/veganism provides a specific opportunity for experiencing liberation and empowerment by one's own consumerism. In a nutshell: it is the taste of freedom and power that constitutes the attractiveness of vegetarianism/veganism. Succeeding in the challenge linked to vegetarianism/veganism can be a trigger for changing one's diet (temporarily). This is especially true for veganism as the more restricted diet. In this regard, it is the challenge of coping with unfamiliar restrictions in particular that drives the change in diet.

One interviewee said that he wanted to test his consistency, strength and power of endurance by restricting himself to veganism for three months. After three months, he extended the period for another six months; he has now been vegan for seven years.

Another participant reported that he had lost a bet and therefore had to be vegan for two months. After that time, he simply stayed vegan because it felt good. In addition, other interviewees stated that they wanted to prove to others or/and themselves that they were able to manage the challenge.

"Empowerment and enrichment" describe promising dynamics that are to be assigned to the tension between "expansion" and "resources". Achieving the ideals of empowerment and enrichment often conflicts with limitations of everyday life regarding, e.g., the availability of preferred food, competencies in preparing food and time constraints (tension between "expansion" and "resources").

\subsection{Gaining Attention and Autonomy}

Vegetarianism/veganism can help generate more attention. This especially, but not exclusively, holds for attention within families. If a child decides to stop eating meat or animal products, it puts pressure on the other family members, e.g., by influencing the diet or having special and different food preparation by those responsible for cooking.

A young woman living in a family with omnivores stated that her parents respect her vegan diet. If the family has meals together, there is always something that fits her diet. The family even adopts vegan dishes, which adjusts to her dietary habits. The same holds for the family of her boyfriend: If she eats with her boyfriend's family, they serve a meatless meal.

Another young woman became vegetarian at the age of eight or nine. She remembered that she received little support. Her mother did not always provide a vegetarian alternative but at least did not attempt to force meat on her. Currently, her mother is open to vegetarianism, and the daughter has the impression that she educated her mother.

In this respect, vegetarianism/veganism can be used as an instrument to develop relationships within a family and/or to change the relational structure. It draws on the relevance of common meals and common nutrition habits for a family or a peer group: to have family meals, the rest of the family, especially those responsible for cooking, have to respect and adjust to the change in diet. If successful, it is possible to maintain family bonds, in line with emancipation and personal differentiation. Vegetarianism/veganism provides a specific opportunity not only to gain attention but also has the power to act as a battlefield for conflicts originating in the family. Classic conflicts between generations can be acted out and/or autonomy can be demonstrated. By opposing traditional nutrition and eating habits, children do not directly defend their interests but those of animals. In this context, vegetarianism/veganism is more of a hidden opposition backed by a moral claim. Still, it can support the process of personal emancipation. 
An independent and self-confident young woman living with her mother feared her mother's reaction to her decision to become vegetarian. In the end, she felt that this was an act of emancipation that loosened the constraints between mother and daughter and changed the relationship. As the daughter, she assumed that she herself was much more open minded compared to her mother and perceived her change to vegetarianism as a detachment from nonreflected traditional eating habits to a more reasoned diet that especially takes the environmental consequences of meat consumption into account.

Exerting the power of vegetarianism/veganism is not limited to children. In addition, adults can impose their own diet on the rest of the family. This especially holds for family members responsible for organizing the purchase and preparation of meals.

One woman stopped buying meat and succeeded in changing the family meals to being meatless, more or less. Even her husband's hunting dog had to become vegan.

In the examples above, the stated reasons for changing the diet referred to animal welfare, the environment and personal health. However, influencing the family and one's position within the family might have been in some cases the primary but possibly unconscious driver. Vegetarianism/veganism enables an increase in attention and exertion of power. Moreover, vegetarianism/veganism offers an opportunity to defend (nonhuman) beings that cannot defend themselves. Thus, vegetarianism/veganism allows people who potentially feel a lack of appreciation from certain parts of their social environment or powerless in their everyday lives to transfer those feelings to animals while experiencing themselves as protectors of those that lack understanding and power. (This mechanism is known in psychology as transference, which is defined " ... as a displacement of aspects of an unconscious mental representation of an infantile object onto a mental representation of a current external object" [71] (p. 42)). The opportunity to gain attention and power by being vegetarian/vegan decreases if, e.g., restaurants offer vegetarian or vegan meals and retailers include these products in their selection. While greater availability reduces the barrier of not eating meat it also makes vegetarianism/veganism less special because the challenge of coping with this special diet declines (see "Empowerment"). In an environment where vegetarianism/veganism are increasing in popularity and are becoming easier to achieve, fruitarian or paleo diets are superior in offering the people the opportunity to feel unique.

"Gaining attention and autonomy" primarily refers to the tension between "impact" and "structure". Cooking and eating concern fundamental structures and customs of human culture. The change in diet influences the social environment. It can lead to a change in the social environment by adapting, e.g., family habits to the preference of vegetarians or vegans, but it can also lead to a permanent rebellion against the eating habits of the social environment.

\subsection{Creating Identity and Superiority}

Independent of the main motivations, vegetarianism/veganism can be used as a means to create a specific self-image and influence one's perception by others. In fact, in some cases, the desire to design a favorable image is the main driver to become vegetarian/vegan.

One participant became vegan in puberty. She stated clearly that she used veganism to feel superior and elitist.

As indicated above, abstaining from eating meat is one way to overcome the dissonance and feelings of guilt that otherwise arise from involvement in an unaccepted production system. Moreover, against the background of society's perception of "factory farming", not eating meat is a playing field for credibly showing and feeling that one is a "good guy". From a moral point of view, one can hardly be blamed for not eating meat because empathy for animals is widespread.

In many interviews, "normal" consumers were characterized as dull and were at least indirectly accused of not thinking about food and the way it is produced. They were blamed for thoughtlessly making use of a system that is regarded as rotten and produces 
low quality food. Food, especially meat, was perceived as too cheap and therefore not sufficiently valued. Consciousness was a major issue in the interviews and makes the participants feel superior.

Especially in situations of food consumption, vegetarianism/veganism has an accusing and separating power in the presence of omnivores. This power can be used to demonstrate ethical superiority but can also lead to social marginalization or even social exclusion.

Several interviewees mentioned that being known as a vegetarian/vegan can provoke reactions from omnivores. Some had the impression that omnivores feel the need to justify their behavior to them and that they seem to ask for some type of absolution for eating meat. Some stated that they feel bothered by the defensive behavior of omnivores and their attempts to justify meat consumption.

The participants also reported that they had to combat the ignorant comments of omnivores. They stated that they attempted to avoid potential conflicts due to their diet in the presence of others and even deviated from the vegetarian/vegan rules or escaped from discussing that topic. These participants also indicated that they are annoyed with people who attempt to create and fuel conflicts between vegetarians/vegans and omnivores.

The aspect of creating identity and superiority is not only relevant between vegetarians/vegans on the one side and omnivores on the other. Rivalry and competition about appropriate behavior among vegetarians/vegans exists as well.

During the group discussions, the participants started accusing each other of not being strict enough or being too strict. Within these disputes, it became obvious that consequences of avoiding animal products or even buying products from companies producing animal products may be perceived by some vegetarians/vegans as too strict and stubborn.

Veganism in particular can be regarded as a higher level of acting that is in line with the idea of not abusing animals. Vegetarianism lacks consequences regarding the use of animals and detangling oneself from "factory farming". In this respect, the idea of an ethically driven vegetarianism is vulnerable as it only extends halfway. Even though this group, especially vegans, is a small niche in German society, they can connect via the digital world, e.g., by creating platforms on the World Wide Web. These platforms are not only used to field arguments but also to build the community. Building worldwide communities and thereby strengthening the feeling of choosing the correct path can balance being special in one's "everyday life" environment. Thus, it helps dissolve the conflict that might arise between being special and feeling excluded.

There is still one additional aspect that should be mentioned: several interviewees had already intensively dealt with the subject before the interviews. The following aspects are reasonable for that kind of dealing with information about an issue that causes discomfort: it is the fascination with nightmarish pictures and imaginations that do not have to be suppressed due to the meatless diet and/or the activation of unpleasant images regarding meat production helps to withstand the temptation of eating meat and/or arguments are collected to justify deviant but superior behavior.

"Creating identity and superiority" also primarily addresses the tension between "impact" and "structure". In contrast to "gaining attention and autonomy"; however, the focus herby is on "impact" with respect to individuality and self-positioning. Moreover, "resources" and "expansion" are addressed as individualism and self-positioning based on ideals and on competences to achieve them.

\subsection{Vegetarianism and Veganism}

Based on the results of the interviews and the systematics of MP, vegetarianism and veganism can be classified in different positions in the impact unit. Adopting a vegetarian lifestyle requires less development and change than a vegan lifestyle. Moreover, vegetarianism is more compatible with everyday life. Consistently vegetarians put more emphasis on the limits and difficulties of implementing a lifestyle without animal products, while vegans are more focused on overcoming these limits. In addition, vegetarians remain 
more in dominating social structures and habits while vegans strive for the ideal of meeting the challenge of not using animal products at all.

Vegetarianism and veganism can thus be positioned differently within the impact unit (Figure 2).

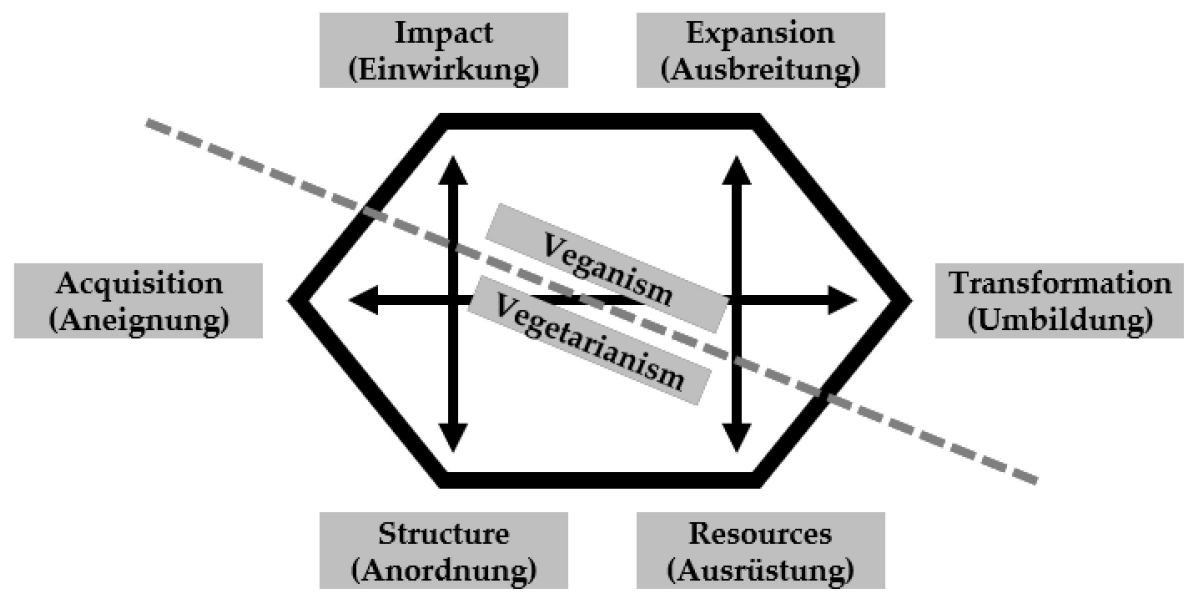

Figure 2. Positioning of vegetarianism and veganism in the impact unit ("Wirkungseinheit"). The terms are the technical terms used in the context of MP. As there is no unambiguously defined translation into English, we put the German terms in brackets in order to emphasize the clear reference to MP.

\section{Discussion}

Vegetarianism/veganism exist in the tense space of avoiding animal products and integrating this ideal into one's everyday life, social relations and the seductive power of an affluent society. The methods of managing this balancing act differ between individuals, as do the motivations.

The paper reveals the specific way in which vegetarianism/veganism can satisfy different motivations using the MP method. MP does not examine psychological personality concepts such as traits, values, attitudes or habits but describes relevant motivations for becoming and remaining vegetarian/vegan and provides a framework to better understand this process and behavior. The obtained findings can be compared to the results of the previous research.

Health, environment and animal welfare have been identified as the main motivations for becoming vegetarian/vegan in previous studies [12,18,19,27,29,30,32,33,46-48]. In our analysis, we find corresponding motivations; environmental reasons still played a minor role. However, as we chose a method that focuses on opportunities for vegetarianism/veganism to address different psychological motivations, our categorization differs. Based on the interviews we identify vegetarianism/veganism as an opportunity to experience liberation from a meat production system that is perceived as rotten and as a personal threat. In this regard vegetarianism/veganism can create empowerment, autonomy, and identity. Improving health, respecting animal welfare as well as mastering the challenge of being vegetarian/vegan can contribute to that process. However, in line with Maurer [46] our results indicate that vegetarianism/veganism can be more or less detached from animal welfare, health and environmental motivations and still have attractiveness referring to, e.g., creating identity or managing social relations.

Providing the opportunity to create identity is identified as one of the important drivers of vegetarianism/veganism in our study. Papers dealing with the conflict arising for vegetarians/vegans in their social environment $[14,15,29,58]$ as well as papers considering vegetarianism/veganism as a political movement $[43,45]$ address this phenomenon, as well. However, in contrast to those papers, we stress the psychological function. While Asher and Cherry [29] concentrate on the relevance of social and family structures for changing 
to a vegetarian/vegan diet, we focus on the opportunities of vegetarianism/veganism in influencing social structures.

The results are close to those of von Essen and Englander [50] and von Essen and Martensson [66] who explored the experience of young adults that choose a healthy lifestyle based on organic food. Vegetarianism/veganism is a reaction on physical signals, contributes to moderating one's condition and feelings as well as to improving vitality and resilience, offers opportunities for creative activities and is embedded in social values.

We confirm the results of previous research (e.g., [14]) that vegetarianism/veganism is typically not driven by one but a blend of several reasons. In this context vegetarianism/veganism offers a specific way with many facets for liberation and empowerment, for gaining attention and autonomy or for creating identity and superiority. According to individual traits, values, attitudes or habits, the relevance of different aspects of vegetarianism/veganism varies between people.

The strength of the method applied in this study is also its weakness. MP relies on empathy between the interviewer and interviewee. Moreover, it is based on interpretation. However, both are necessary to understand emotional and unconscious contexts, the lack of which might lead to an inappropriate reconstruction of phenomena. By conducting the study with a team of experienced psychologists we made every effort to ensure that the interpretation presented covers all relevant aspects and thus is able to provide deeper insights into the research question. Nevertheless, the findings presented remain an interpretation of the involved research team.

Although our sample size can be considered adequate to large in comparison to similar qualitative studies [72], we did not include vegetarians/vegans who operate at the edge of legality, potentially conducting even illegal actions to improve the animal welfare and animal rights situation. Thus, this aspect of vegetarianism/veganism was not investigated in this study.

\section{Conclusions}

Opportunities, challenges, and fascination with vegetarianism/veganism appear clear from the analysis of the interviews and confirm as well as partly add insights to previous studies. Furthermore, our analysis provides a hypothesis to answer why, in light of all the harm society faces, such as starvation, child labor or, closer to home, unsatisfying geriatric care, people concentrate on animals and the meat production sector. If it was just empathy that drives action, the other problems should attract at least similar attention. However, our study shows that vegetarianism/veganism is one way to experience liberation and empowerment in an affluent society. Vegetarianism/veganism offers opportunities for creating and demonstrating one's own identity. In addition, it allows people to experience themselves as actors. Changing one's diet demonstrates to oneself and others that one is actively contributing to what is perceived as an overall positive change while at the same time expressing opposition to a rejected development. This might also serve as a type of balancing strategy to justify the neglect of other potentially even more severe problems.

Still, it has to be considered that the focus of the study was to get a deeper insight into the fascinating aspects of vegetarianism/veganism. The sample only comprised self-reported vegetarians and vegans. The approach allows for a deeper insight into the motivational structure with respect acceptance. However, the study did not focus on obstacles to the adoption of a plant-based lifestyle or on the motivational structure of meat eating. Moreover, the motivational structures of people that intend to limit their meat consumption or to avoid meat in the future are not explicitly addressed by the study. This leaves a wide field for additional research. MP has shown to provide an appropriate theoretical background and methodological approach to obtain deeper insights into the psychological drivers for choosing a special diet. The results may contribute to a more comprehensive understanding to vegetarianism and veganism.

Author Contributions: Conceptualization, J.S., C.V., I.H.; formal analysis, J.S., C.V., I.H.; investigation, J.S., C.V., I.H.; resources, J.S., C.V., I.H., J.K-L., M.H.; data curation, J.S., C.V., I.H.; writing- 
original draft preparation, J.S., J.K.-L., M.H.; writing-review and editing: J.S., C.V., J.K.-L., M.H.; supervision, J.S., J.K.-L., M.H.; project administration, J.S., J.K-L., M.H.; funding acquisition: J.S., M.H., methodology: J.S., C.V., I.H. All authors have read and agreed to the published version of the manuscript.

Funding: The project was supported by funds of the Federal Ministry of Food and Agriculture (BMEL) based on a decision of the Parliament of the Federal Republic of Germany via the Federal Office for Agriculture and Food (BLE) under the innovation support program. Grant number 2817203113.

Institutional Review Board Statement: Ethical review and approval were waived for this study, due to the fact that it was not a medical one, subjects were not exposed to any harm, their rights were protected, and every precaution was taken in order to protect the privacy of research subjects and the confidentiality of their personal information.

Informed Consent Statement: Informed consent was obtained from all subjects involved in the study.

Data Availability Statement: Not applicable.

Conflicts of Interest: The authors declare no conflict of interest.

Ethics Statement: All subjects gave their informed consent for inclusion before they participated in the study.

\section{References}

1. Joy, M. Why We Love Dogs, Eat Pigs, and Wear Cows: An Introduction to Carnism; Red Wheel: Newburyport, MA, USA, 2011.

2. Albersmeier, F.; Spiller, A. Das Ansehen der Fleischwirtschaft: Zur Bedeutung einer stufenübergreifenden Perspektive. In Die Ernährungswirtschaft im Scheinwerferlicht der Öffentlichkeit. Reihe: Agrarökonomie; Eul-Verlag: Siegburg, Germany, 2009; Volume 4, pp. 213-250.

3. Heise, H.; Theuvsen, L. What do consumers think about farm animal welfare in modern agriculture? Attitudes and shopping behaviour. Int. Food Agribus. Manag. Rev. 2017, 20, 379-399. [CrossRef]

4. Busch, G.; Kayser, M.; Spiller, A. „Massentierhaltung “aus VerbraucherInnensicht-Assoziationen und Einstellungen. Jahrbuch der Österreichischen Gesellschaft für Agrarökonomie 2013, 22, 61-70.

5. Christoph-Schulz, I.; Salamon, P.; Weible, D. What is the benefit of organically-reared dairy cattle? Societal perception towards conventional and organic dairy farming. Int. J. Food Syst. Dyn. 2015, 6, 139-146.

6. Spiller, A. Zukunftsperspektiven der Fleischwirtschaft: Verbraucher, Märkte, Geschäftsbeziehungen; Universitätsverlag Göttingen: Göttingen, Germany, 2008.

7. Kohlmüller, M.; Koch, T. AMI Marktbilanz Vieh und Fleisch 2020: Daten, Fakten, Entwicklungen Deutschland, EU, Welt; Agrarmarkt Informations-Gesellschaft mbH: Bonn, Germany, 2020.

8. Mintel. Healthy Lifestyles. Available online: https://downloads.mintel.com/private/AcTts/files/638971/ (accessed on 2 March 2021).

9. Statista. Anzahl der Veganer in Deutschland 2020. Available online: https://de.statista.com/statistik/daten/studie/445155 / umfrage/umfrage-in-deutschland-zur-anzahl-der-veganer/ (accessed on 2 March 2021).

10. Statista. Lebenseinstellung —Vegetarier in Deutschland 2020. Available online: https://de.statista.com/statistik/daten/studie/ 173636/umfrage/lebenseinstellung-anzahl-vegetarier/ (accessed on 2 March 2021).

11. Statista. Vegane Gastronomiebetriebe: Anzahl in Deutschland bis 2020. Available online: https://de.statista.com/statistik/ daten/studie/381076/umfrage/anzahl-veganer-gastronomiebetriebe-in-deutschland/ (accessed on 2 March 2021).

12. Ruby, M.B. Vegetarianism. A blossoming field of study. Appetite 2012, 58, 141-150. [CrossRef] [PubMed]

13. Rosenfeld, D.L. The psychology of vegetarianism: Recent advances and future directions. Appetite 2018, 131, 125-138. [CrossRef]

14. Beardsworth, A.; Keil, T. The vegetarian option: Varieties, conversions, motives and careers. Sociol. Rev. 1992, 40, 253-293. [CrossRef]

15. Jabs, J.; Sobal, J.; Devine, C.M. Managing vegetarianism: Identities, norms and interactions. Ecol. Food Nutr. 2000, 39, 375-394. [CrossRef]

16. Greenebaum, J. Veganism, identity and the quest for authenticity. Food Cult. Soc. 2012, 15, 129-144. [CrossRef]

17. Shapiro, K.J. "I am a Vegetarian": Reflections on a Way of Being. Soc. Anim. 2014, 20, 128-147.

18. De Backer, C.J.S.; Hudders, L. Meat morals: Relationship between meat consumption consumer attitudes towards human and animal welfare and moral behavior. Meat Sci. 2015, 99, 68-74. [CrossRef] [PubMed]

19. Izmirli, S.; Phillips, C.J.C. The relationship between student consumption of animal products and attitudes to animals in Europe and Asia. Br. Food J. 2011, 113, 436-450. [CrossRef]

20. Kerschke-Risch, P. Vegan diet: Motives, approach and duration. Initial results of a quantitative sociological study. ErnahrungsUmschau 2015, 62, 98-103.

21. Rothgerber, H. A meaty matter. Pet diet and the vegetarian's dilemma. Appetite 2013, 68, 76-82. [CrossRef] 
22. Rothgerber, H. A comparison of attitudes toward meat and animals among strict and semi-vegetarians. Appetite 2014, 72, 98-105. [CrossRef] [PubMed]

23. Rothgerber, $\mathrm{H}$. Underlying differences between conscientious omnivores and vegetarians in the evaluation of meat and animals. Appetite 2015, 87, 251-258. [CrossRef] [PubMed]

24. Ruby, M.B.; Heine, S.J. Meat, morals, and masculinity. Appetite 2011, 56, 447-450. [CrossRef] [PubMed]

25. Modlinska, K.; Adamczyk, D.; Maison, D.; Pisula, W. Gender Differences in Attitudes to Vegans/Vegetarians and Their Food Preferences, and Their Implications for Promoting Sustainable Dietary Patterns-A Systematic Review. Sustainability 2020, $12,6292$. [CrossRef]

26. Rimal, A.P. Factors affecting meat preferences among American consumers. Fam. Econ. Nutr. Rev. 2002, 14, 36.

27. Janssen, M.; Busch, C.; Rödiger, M.; Hamm, U. Motives of consumers following a vegan diet and their attitudes towards animal agriculture. Appetite 2016, 105, 643-651. [CrossRef] [PubMed]

28. Piazza, J.; Ruby, M.B.; Loughnan, S.; Luong, M.; Kulik, J.; Watkins, H.M.; Seigerman, M. Rationalizing meat consumption. The 4Ns. Appetite 2015, 91, 114-128. [CrossRef] [PubMed]

29. Asher, K.; Cherry, E. Home Is Where the Food Is: Barriers to Vegetarianism and Veganism in the Domestic Sphere. J. Crit. Anim. Stud. 2015, 13, 66-99.

30. Cherry, E. I was a teenage vegan: Motivation and maintenance of lifestyle movements. Sociol. Inq. 2015, 85, 55-74. [CrossRef]

31. Lönneker, J. Die Wirkung von Qualitäten-Gestalten im Wandel. In Qualitative Marktforschung in Theorie und Praxis; Naderer, G., Balzer, E., Eds.; Gabler Publishing House: Weisbaden, Germany, 2011; pp. 83-110.

32. Ruby, M.B.; Heine, S.J.; Kamble, S.; Cheng, T.K.; Waddar, M. Compassion and contamination. Cultural differences in vegetarianism. Appetite 2013, 71, 340-348. [CrossRef] [PubMed]

33. Ulusoy, E. I think, therefore i am vegan: Veganism, ethics, and social justice. In Marketing as Provisioning Technology: Integrating Perspectives on Solutions for Sustainability, Prosperity, and Social Justice. Proceedings of the 40th Annual Macromarketing Conference, Chicago, USA, 25-28 June 2015; Shultz, C., II, Benton, R., Kravets, O., Eds.; Macromarketing Society Inc: Laramie, WY, USA, 2015.

34. Ruby, M.B.; Heine, S.J. Too close to home. Factors predicting meat avoidance. Appetite 2012, 59, 47-52. [CrossRef] [PubMed]

35. Bratanova, B.; Loughnan, S.; Bastian, B. The effect of categorization as food on the perceived moral standing of animals. Appetite 2011, 57, 193-196. [CrossRef] [PubMed]

36. Loughnan, S.; Bratanova, B.; Puvia, E. The Meat Paradox: How are we able to love animals and love eating animals. Mind Italia 2011, 1, 15-18.

37. Fox, N.; Ward, K.J. You are what you eat? Vegetarianism, health and identity. Soc. Sci. Med. 2008, 66, 2585-2595. [CrossRef] [PubMed]

38. Sneijder, P.; Te-Molder, H. Normalizing ideological food choice and eating practices. Identity work in online discussions on veganism. Appetite 2009, 52, 621-630. [CrossRef]

39. Nezlek, J.B.; Forestell, C.A. Vegetarianismas a social identity. Curr. Opin. Food Sci. 2020, 33, 45-51. [CrossRef]

40. Hsiao, T. In defense of eating meat. J. Agric. Environ. Ethics 2015, 28, 277-291. [CrossRef]

41. Erdős, L. Veganism versus meat-eating, and the myth of "root capacity": A response to Hsiao. J. Agric. Environ. Ethics 2015, 28, 1139-1144. [CrossRef]

42. McDonald, B. "Once You Know Something, You Can't Not Know It" An Empirical Look at Becoming Vegan. Soc. Anim. 2000, $8,1-23$.

43. Wrenn, C.L. Resisting the globalization of speciesism: Vegan abolitionism as a site for consumer-based social change. J. Crit. Anim. Stud. 2011, 9, 9-27.

44. Micheletti, M.; McFarland, A.S. Creative Participation: Responsibility-Taking in The Political World; Routledge: Abingdon, UK, 2015.

45. Adams, C.J. The Sexual Politics of Meat: A Feminist-Vegetarian Critical Theory; Bloomsbury Publishing: New York, NY, USA, 2015.

46. Beardsworth, A.D.; Keil, E.T. Vegetarianism, veganism, and meat avoidance: Recent trends and findings. Br. Food J. 1991, 93, 19-24. [CrossRef]

47. Fox, N.; Ward, K. Health, ethics and environment: A qualitative study of vegetarian motivations. Appetite 2008, 50, 422-429. [CrossRef] [PubMed]

48. Rozin, P.; Markwith, M.; Stoess, C. Moralization and becoming a vegetarian: The transformation of preferences into values and the recruitment of disgust. Psychol. Sci. 1997, 8, 67-73. [CrossRef]

49. Greger, M. How Not to Die: Discover the Foods Scientifically Proven to Prevent and Reverse Disease; Pan Books: London, UK, 2018.

50. Von Essen, E.; Englander, M. Organic food as a healthy lifestyle: A phenomenological psychological analysis. Int. J. Qual. Stud. Health Well-Being 2013, 8, 20559. [CrossRef]

51. Von Essen, E.; Mårtensson, F. Young adults' use of food as a self-therapeutic intervention. Int. J. Qual. Stud. Health Well-being 2014, 9, 23000. [CrossRef]

52. Larsson, C.L.; Klock, K.S.; Åstrøm, A.N.; Haugejorden, O.; Johansson, G. Food habits of young Swedish and Norwegian vegetarians and omnivores. Public Health Nutr. 2001, 4, 1005-1014. [CrossRef]

53. Larsson, C.L.; Klock, K.S.; Åstrøm, A.N.; Haugejorden, O.; Johansson, G. Lifestyle-related characteristics of young low-meat consumers and omnivores in Sweden and Norway. J. Adolesc. Health 2002, 31, 190-198. [CrossRef]

54. Duve, K. Anständig Essen: Ein Selbstversuch; Kiepenheuer \& Witsch: Köln, Germany, 2010. 
55. Hirschler, C.A. “What pushed me over the edge was a deer hunter": Being Vegan in North America. Soc. Anim. 2011, 19, 156-174. [CrossRef]

56. Maurer, D. Vegetarianism: Movement or moment? Promoting A Lifestyle for Cult Change Philadelphia; Temple University Press: Philadelphia, PN, USA, 2002.

57. Lawo, D.; Esau, M.; Engelbutzeder, P.; Stevens, G. Going Vegan: The Role (s) of ICT in Vegan Practice Transformation. Sustainability 2020, 12, 5184. [CrossRef]

58. Greenebaum, J. Managing Impressions: “Face-Saving” Strategies of Vegetarians and Vegans. Humanity Soc. 2012, 36, 309-325. [CrossRef]

59. Nezlek, J.B.; Cypryanska, M.; Forestell, C.A. Dietary Similarity of Friends and Lovers: Vegetarianim, Omnivorism, and Personal Relationships. J. Soc. Psychol. 2020, 1-7. [CrossRef]

60. Mylan, J. Sustainable consumption in everyday life: A qualitative study of UK consumer experiences of meat reduction. Sustainability 2018, 10, 2307. [CrossRef]

61. Cooney, N. Veganomics: The Surprising Science on What Motivates Vegetarians, From the Breakfast Table to the Bedroom; Lantern Books: New York, NY, USA, 2013.

62. Fessler, D.M.T.; Arguello, A.P.; Mekdara, J.M.; Macias, R. Disgust sensitivity and meat consumption: A test of an emotivist account of moral vegetarianism. Appetite 2003, 41, 31-41. [CrossRef]

63. MacNair, R. McDonald's “Empirical Look at Becoming Vegan”. Soc. Anim. 2001, 9, 63-69. [CrossRef]

64. Ziems, D. The morphological approach for unconscious consumer motivation research. J. Advert. Res. 2004, 44, 210-224. [CrossRef]

65. Salber, W. Wirkungseinheiten-Psychologie von Werbung und Erziehung, 2nd ed; Moll \& Hülser: Köln, Germany, 1981.

66. Salber, D. Wirklichkeit im Wandel. Einführung in die Morphologische Psychologie; Bouvier: Bonn, Germany, 2009.

67. Melchers, C.; Ziems, D. Morphologische Marktpsychologie; LIT: Münster, Germany, 2001.

68. Fitzek, H. Morphologische Beschreibung. In Handbuch Qualitative Forschung in der Psychologie; Springer: Wiesbaden, Germany, 2020; pp. 692-706.

69. Reik, T. Listening with The Third Ear; Macmillan: New York, NY, USA, 1983.

70. Dilthey, W. Ideen über Eine Beschreibende und zergliedernde Psychologie; Verlag der Königlichen Akademie der Wissenschaften: Berlin, Germany, 1894.

71. Blum, H.P. On the conception and development of the transference neurosis. J. Am. Psychoanal. 1971, 19, 41-53. [CrossRef]

72. Szmigin, I.; Carrigan, M.; McEachern, M.G. The conscious consumer: Taking a flexible approach to ethical behaviour. Int. J. Consum. Stud. 2009, 33, 224-231. [CrossRef] 